\title{
Tom Regan's Seafaring Dog and (Un)Equal Inherent Worth
}

\author{
Rem B. Edwards \\ University of Tennessee
}

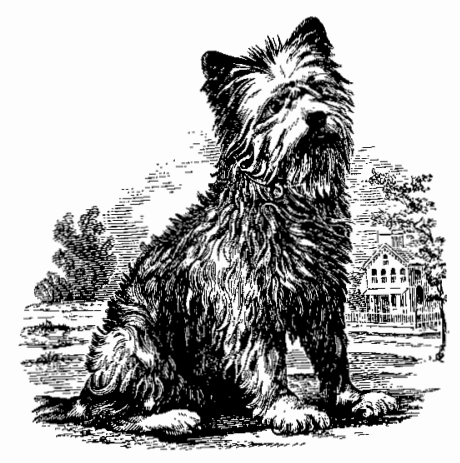

Tom Regan's seafaring dog that is justifiably thrown out of the lifeboat built for four to save the lives of four humans has been the topic of much discussion. Critics have argued in a variety of ways that this dog nips at Regan's achilles heel. Without reviewing previous discussions, with much of which I certainly agree, I wish to develop an unexplored approach to exposing the vulnerability of the position which Regan takes on sacrificing the dog to save the humans. I will argue that when dealing with the seafaring dog Regan abandons his own principles and that this is exactly what he should do. Regan should abandon his view that all subjectsof-a-life have equal inherent worth.

\section{Inherent and Intrinsic Worth}

Regan makes a theoretically significant distinction between two kinds of value, intrinsic and inherent. Intrinsically valuable things are experiences like pleasures or preference satisfactions.' Inherently valuable things are individual subjects of a life. ${ }^{2}$ Presumably, both intrinsic and inherent values are desirable for their own sakes and are ends in themselves. Regan fails to make a clear conceptual or definitional

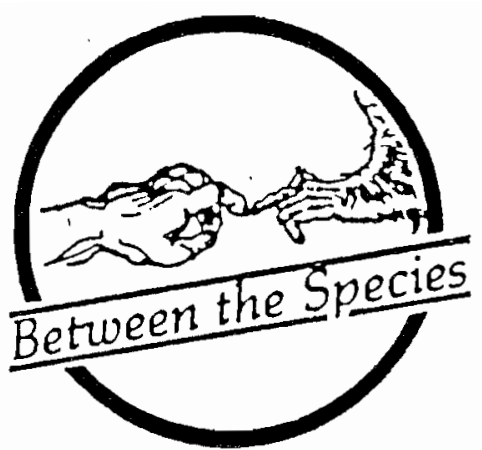

distinction between intrinsic and inherent values. He recognizes that intrinsic value has been defined as: "what is desired for its own sake," "what would be good even if it existed in isolation from everything else, what ought to exist for its own sake," and "what is valued or preferred in itself."3 But inherent values are defined in much the same language as "having value in themselves," 4 or as "ends in themselves." 5 Regan differentiates between intrinsic and inherent values primarily by example rather than formally or conceptually, and this distinction would work just as well as a pluralistic theory of intrinsic good which affirms that more than one kind of thing-e.g. pleasures and individuals - are valuable in and of themselves.

Nevertheless, inherent values are incommensurate with and not reducible to intrinsic values, Regan insists. A pluralistic theory of intrinsic value could also make such a claim. Regan explains that "we cannot determine the inherent value of individual moral agents by totaling the intrinsic values of their experiences. Those who have a more pleasant or happier life do not therefore have greater inherent value than those whose lives are less pleasant or happy." 7 This could be just as well expressed by saying that individual subjects-of-a-life and their pleasant experiences both have intrinsic value and that the value of the former is incommensurate with and not reducible to the value of the latter. I will continue to use Regan's language, however.

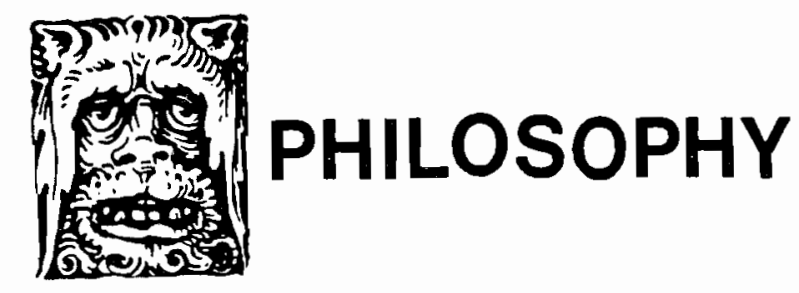




\section{Subjects-of-a-life are described as having}

beliefs and desires; perception, memory, and a sense of the future, including their own future; an emotional life together with feelings of pleasure and pain; preference and welfareinterests; the ability to initiate action in pursuit of their desires and goals; a psychophysical identity over time; and an individual welfare in the sense that their experiential life fares well or ill for them, logically independently of their utility for others and logically independently of their being the object of anyone else's interests. ${ }^{7}$

Not all animals are subjects-of-a-life, but normal mammals a year old or more clearly are; and many other animals who lack some of the above traits should be given the benefit of the doubt, Regan thinks. ${ }^{8}$ I will follow Regan in using the word "animal" hereafter to refer to those which clearly are subjects-of-a-life. Both moral agents who have moral duties and moral patients to whom duties are owed are subjects-of-a-life (at least if they are normal mammals a year old or more) and thus are inherently valuable. ${ }^{9}$

Regan insists that all animals (in the above sense) have equal inherent value, that the notion is categorical and not comparative; but the experiences of individual animals may have very unequal intrinsic value. Conscious individuals may differ significantly in pleasures or desire satisfactions while remaining equal as subjects-of-a-life. Regan correctly affirms that traditional utilitarians, who emphasize pleasures or desire satisfactions, and perfectionists, who emphasize virtues and talents, recognize only intrinsic value but not inherent value in individual centers of conscious experience and activity. According to these ethical theories, individual centers of conscious experience and activity have the instrumental worth of an empty bucket or receptacle into which intrinsically good stuff like pleasures or talents can be poured; but the receptacles themselves have no intrinsic or inherent worth. Traditional utilitarianism and perfectionism did not recognize that individuals are ends in themselves. ${ }^{10}$

I think we should agree with Regan that individual centers of conscious experience, whether human or nonhuman, are valuable in and of themselves and that their value is more than the sum of the value of the universal and repeatable goods like pleasure, talent, knowledge, virtue, or what have you, that they exemplify. ${ }^{11}$ I will not argue further for this here, but obviously this claim may be accepted while rejecting Regan's further claim that all animals (normal mammals) have equal inherent worth because they are all equally subjects-of-a-life. Regan contends "subject-of-a-life" is a categorical concept, that there can not be degrees of it "depending on the degree to which they have or lack some favored ability or virtue." 12

Despite Regan's insistence to the contrary, it seems to me that there are degrees of being the subject-of-alife. By degrees I mean that subjects-of-a-life differ immensely with respect to

1. the complexity of their organization,

2. the extent to which they exemplify the defining characteristics of the notion, and

3. the richness with which they may manifest additional traits of subjectivity conspicuously absent from Regan's list like rationality, selfconsciousness, moral agency, etc..

All of the defining characteristics in Regan's notion of a subject-of-a-life are ability or capacity concepts, and there can be and indeed are all sorts of degrees of each of these characteristics to be found among species of normal mammals, humans included. Regan does not pick just one or two favored abilities or virtues; he picks a large assortment of them. Yet, all of the abilities Regan includes can and do exist as degrees of ability or capacity and as actualized properties in various species and individuals.

Regan does not avoid favoring preferred abilities (perfectionism) just because his list includes a large conglomeration of them! Look carefully at his concept of subject-of-a-life and you will realize that among mammals there are many degrees of the abilities to have beliefs, desires, perceptions, memories, a sense of the future including one's own, emotions, feelings of pleasure and pain, preference and welfare interests, ability to initiate action in pursuit of desires and goals, psychophysical identity over time, and individual welfare. It may be difficult and at times impossible to measure carefully and compare all of these differences, but they clearly exist among subjects-of-a-life, and they are the defining characteristics of such subjects.

It might be replied that all mammals as wholes are still equally subjects-of-a-life even though their parts differ in degrees, that the preceding argument commits a fallacy of composition. However, it is not always a fallacy to reason from parts to wholes; ${ }^{13}$ and it is not at 
all implausible that if two mammals (say a human and a dog) differ significantly in their capacities for emotions, satisfactions, pleasures and pains, etc., they differ in the degree to which they are subjects-of-a-life since these are among the defining characteristics of such subjects. It might also be replied that being the subject-of-a-life consist not simply of the presence of these defining abilities but also of the unique way in which they are integrated into the complex subjectivity of each distinctive individual. Unfortunately, this turn to uniqueness can not be used to defend Regan's contention that all mammals are subjects-of-a-life equally. The latter is presumably something they all have in common, but uniqueness is something by which they all differ. Of course, all unique things have uniqueness in common, but since uniqueness means being different, this says only that what they have in common is being different, not that they are equally subjects of a life. Regan should conclude that animals are not all equal with respect to the value of being unique subjects-of-alife because they differ immensely with respect to the complexity and richness of their properties as such.

\section{Regan's Seafaring Dog}

Let us now apply the above reflections to the case of Regan's ill fated dog who must be cast overboard to save the lives of four humans on a four person only raft. Is it right or wrong for the four persons to jettison the dog to save themselves? Regan insists that to harm individual subjects-of-a-life

merely in order to produce the best consequences for all involved-is to treat them unjustly-because it fails to respect their inherent value. To borrow part of a phrase from Kant, individuals who have inherent value must never be treated merely as a means to securing the best aggregate consequences. ${ }^{14}$

By the best aggregate consequences Regan means the given totality of the intrinsic values of pleasure, preference fulfillment, etc. Applied to the lifeboat situation, it would appear at first to be unjust to harm (i.e. drown) the dog merely to produce the best aggregate consequences for the four humans because doing so would fail to respect the dog's inherent value and would treat it merely as a means to securing the most pleasure, preference fulfillment, etc. for the men.
However, Regan's worse-off principle is supposed to save the day for the humans and doom the dog. Regan writes that "Our belief that it is the dog who should be killed is justified by appeal to the worse-off principle."15 Regan's miniride principle would allow sacrificing the life of one individual where necessary to save the lives of many when harms to each are comparable; but his worse-off principle forbids sacrificing the life of one individual where necessary to save the lives of many when the harms to each are not comparable. However, it permits sacrificing the life of one individual to save a second individual if the death of the second would be worse than the death of the first. ${ }^{16}$ Thus, if the harm that would befall the dog if drowned is comparable to the harm that would befall each of the humans if drowned, it would be wrong to sacrifice the dog. Regan argues, however, that the harms would not be comparable, that the death of the person would be worse than the death of the dog, and that it is therefore justifiable to drown the dog. Indeed, for this reason it would be justifiable if necessary to throw a million dogs overboard to save one human. ${ }^{17}$ As Regan expresses it,
All on board [the lifeboat] have equal inherent value and an equal prima facie right not to be harmed. Now, the harm that death is, is a function of the opportunities for satisfaction it forecloses, and no reasonable person would deny that the death of any of the four humans would be a greater prima facie loss, and thus a greater prima facie harm, than would be true in the case of the dog. Death for the dog, in short, though a harm, is not comparable to the harm that death would be for any of the humans. To throw any one of the humans overboard, to face certain death, would be to make that individual worse-off (i.e. would cause that individual a greater harm) than the harm that would be done to the dog if the animal was thrown overboard. ${ }^{18}$

It is indeed unfortunate that Regan seems to forget his distinction between inherent and intrinsic value when he analyzes the harm of death. His great failure here is that he focuses exclusively on the loss of opportunities for the realization of intrinsic value ("satisfaction"). However, if individual subjects-of-alife do indeed have inherent value as well as opportunities for the realization of intrinsic value, surely 
death involves much greater harm than a mere loss of opportunities for satisfaction. It also involves the extinction and loss of all the inherent worth of being a unique subject-of-a-life. If Regan is right that this is equal for all such subjects, then death is just as great a loss in this important respect for the dog as for the humans.

It is true that normal humans would typically have more opportunities for satisfaction than a normal dog. This might not be so in the unusual circumstances described by Judith Barad-Andrade in which the four humans at sea all "work in the same assembly line..., have a cynical attitude toward life, are companionless, and when not at work can almost always be found in front of the television set," and the seafaring dog by contrast "has close ties with her human family, has puppies waiting for her at home, enjoys riding in the car and long walks, and has an interest in investigating new places and meeting new creatures" and has recently "displayed her courage and loyalty by rescuing a young friend from a burning building." "B But let us assume that the dog is a couch potato and the humans are intensely involved morally and aesthetically with others and with the world. Then their opportunities for satisfaction would, as Regan suggests, outweigh those of the dog; but this shows only that their loss of intrinsic value would be greater. It does not show that their loss of inherent value would be greater than the dog's loss of the same. In fact, their lost of inherent value would be identical if Regan is right that all subjects-of-a-life have equal inherent worth. Regan claims that "The selection of the dog does not conflict with recognizing the animal's equal inherent value..." ${ }^{20}$ but it most certainly does because it ignores the fact that extinction of the animal's inherent value would be just as great a loss for it as would the extinction of one of the human's inherent value, if indeed their inherent values are equal. Regan seems to think that casting the dog overboard is not incompatible with recognizing its equal inherent value because the dog's losses are not outweighed by summing up the losses of the group of humans in the lifeboat, ${ }^{21}$ but the real incompatibility arises simply by not allowing equal inherent value to count and by basing the choice upon the unequal intrinsic worth of the dog and one of the humans. Equal rights supposedly depend on equality of inherent worth, but in the lifeboat situation inequalities of intrinsic worth give the person stronger rights to life and freedom from harm.

Regan considers the possibility that those in the lifeboat should draw straws as an expression of equal respect for each contender for life instead of sacrificing the dog in preference to one of the humans; but he rejects this possibility on the grounds that "no reasonable person would suppose that the dog has a 'right to life' that is equal to the humans' or that the animal should be given an equal chance in the lottery for survival." 22 However, a lottery like drawing straws is precisely the correct moral strategy for choosing among equals when lifesaving resources are too scarce to save all. Regan rejects a lottery only at the price of ignoring his own cherished doctrine of equality of inherent worth among subjects-of-a-life. In the final analysis, on Regan's view, all that we need to consider is unequal intrinsic worth.

Regan's resolution of the lifeboat case depends entirely upon inequalities of intrinsic value, despite equalities of inherent value. He may not aggregate these by summing up the future pleasures or satisfactions of all four of the human survivors and weighing these against the future pleasures or satisfactions of one dog or even a million dogs; but it is unclear why this should not be done once the decision has been made to regard the loss of intrinsic values as the only undesirable consequence of death. Regan certainly does aggregate the future satisfactions of the one dog and weigh them to find them wanting compared to the future satisfactions of one of the humans. If satisfactions can be aggregated and compared within two individuals, why shouldn't they be aggregated between many individuals? Regan simply ignores the supposedly equal inherent worths of the man and the dog, and justifies drowning the dog solely on the basis of inequalities of future satisfactions, i.e. on differences of intrinsic value, or on the best aggregate consequences. It is as if Regan thinks that equal inherent worths cancel out one another when one life must be chosen against another. Regan insists that "individuals who have inherent value are not to be treated as if they were mere 'receptacles' of valuable experiences (e.g., pleasures)..."23; but once equal inherent values are allowed to cancel out one another, what remains is merely individuals as receptacles.

If I am right, however, that all subjects-of-a-life do not have equal inherent worth, and if, as they typically are, the human subjects-of-a-life are indeed much more complex, intense, and richer in properties than that of the dog, then casting the dog overboard is justified both in terms of inherent and intrinsic value. The dog has both less inherent worth as a unique individual and fewer opportunities for future satisfactions than the humans, and for both of these reasons it is unreasonable 
to suppose that the dog has a right to life that is equal to that of the humans or that it should be given an equal chance in the lottery for survival.

There is a sense, of course, in which planet earth is a giant lifeboat situation in which some individuals must die to save others from death. Much human experimentation on animals is commercial rather than medical, and much medical experimentation aims at developing the means to prevent harms (like discomforts, dysfunctions, or deformities) that are less severe than the loss of life. Still, some medical experimentation on animals clearly aims at saving lives or preventing premature deaths for both animals and humans. Both Regan's reasoning and my own would seem to justify such experimentation on animals, especially if it has a reasonable probability of success. Indeed, Regan's reasoning would justify terminal experiments on millions of animals just to save one normal human being. Either the animals or the person will die prematurely, the former in terminal medical experiments, the latter from some terminal disease for which we presently have no cure. In considering toxicity tests of new drugs, Regan argues that animals should not be used because they have not voluntarily placed themselves at risk for such perils, ${ }^{24}$ but Regan does not consider whether the seafaring dog voluntarily agreed to go to sea. In the lifeboat situation, this consideration is irrelevant, so it should be equally irrelevant in the lifeboat of toxicity testing. So, should the animals be "thrown overboard" to save the human? Regan's answer must be affirmative, given his solution to the case of the seafaring dog, because anticipated harms to each are incomparable, i.e. because the loss of opportunities for satisfaction for the person is much greater than the loss of satisfaction for any one of the animals. I would agree, but I would add that the loss of the inherent worth of being the subjectof-a-life is also greater for the person than for the dog, because the inherent worth of each is also incomparable.

\section{Notes}

1 Tom Regan, The Case for Animal Rights, Berkeley, University of California Press, 1983, p. 235.

$$
\begin{aligned}
& { }^{2} \text { Ibid., p. } 243 . \\
& { }^{3} \text { Ibid., p. } 142 . \\
& { }^{4} \text { Ibid., p. } 235 . \\
& { }^{5} \text { Ibid., p. } 239 . \\
& { }^{6} \text { Ibid., pp. } 235,236 .
\end{aligned}
$$

${ }^{7}$ Ibid., p. 243.

${ }^{8}$ Ibid., pp. 76-78, 246-247, 391.

${ }^{9}$ Ibid., p. 244.

${ }^{10}$ Ibid., p. 236.

11 Under the influence of Robert S. Hartman, I have developed my own affirmation of the distinctive intrinsic value of individual centers of conscious experience and activity in my "Universals, Individuals and Intrinsic Good" in Rem B. Edwards and John W. Davis, eds., Forms of Value and Valuation: Theory and Applications, Lanham, MD, University Press of America, 1991, pp. 81-104.

${ }^{12}$ Regan, p. 244.

${ }^{13}$ On reasoning correctly from parts to wholes, see Rem B. Edwards, Reason and Religion, New York, Harcourt Brace Jovanovich, 1972, and Lanham, MD, University Press of America, 1979, pp. 264-267.

${ }^{14}$ Regan, p. 249.

${ }^{15}$ Ibid., p. 324.

${ }^{16}$ Ibid., pp. 305-312. Formally stated, Regan's miniride principle says:

Special considerations aside, when we must choose between overriding the rights of many who are innocent or the rights of few who are innocent, and when each affected individual will be harmed in a prima facie comparable way, then we ought to choose to override the rights of the few in preference to overriding the rights of the many. (p. 305)

Regan's worse-off principle says:

Special considerations aside, when we must decide to override the rights of the many or the rights of the few who are innocent, and when the harm faced by the few would make them worse-off than any of the many would be if any other option were chosen, then we ought to override the rights of the many. (p. 308)

${ }^{17}$ lbid., p. 325.

${ }^{18}$ Ibid., p. 324.

19 Judith Barad-Andrade, "The Dog in the Lifeboat Revisited," Between the Species, Vol. 8, no. 2, Spring 1992, p. 116.
${ }^{20}$ Regan, p. 324.
${ }^{21}$ Ibid., p. 325.
22 Ibid., p. 285-6.
23 Ibid., p. 277.
24 Ibid., p. 337. 